\title{
3 Research Square \\ Sex Differences in Blood Pressure and the Kidney Cortex Transcriptome in Nonhuman Primates
}

\section{Angelica M Riojas}

Wake Forest School of Medicine https://orcid.org/0000-0002-4918-407X

Kimberly D. Spradling-Reeves

Wake Forest School of Medicine

Robert E. Shade

Texas Biomedical Research Institute

Sobha R. Puppala

Wake Forest School of Medicine

Clinton L. Christensen

Texas Biomedical Research Institute

Shifra Birnbaum

Texas Biomedical Research Institute

Jeremy P. Glenn

Texas Biomedical Research Institute

Shannan Hall-Ursone

Texas Biomedical Research Institute

Laura A. Cox ( $D$ laurcox@wakehealth.edu )

Wake Forest School of Medicine

\section{Research Article}

Keywords: Hypertension, WGCNA, genetics, kidney, precision medicine, baboon

Posted Date: October 22nd, 2021

DOI: https://doi.org/10.21203/rs.3.rs-723028/v2

License: (c) (1) This work is licensed under a Creative Commons Attribution 4.0 International License.

Read Full License 


\section{Abstract}

Hypertension is a complex disease influenced by sex, and genetic and environmental factors. Blood pressure (BP) is a continuous trait that is heritable in primates, including humans and baboons. The kidneys play a role in systemically regulating BP. Sex differences in BP onset and control with antihypertensive drug therapies have been observed in humans and rodents. Hypertension studies in nonhuman primates (NHP) to date have focused on males. We hypothesized that there are differences in renal molecular networks associated with BP in female and male primates. Sodium-naïve female $(n=8)$ and male $(n=9)$ baboons were fed a low-sodium chow diet prior to and during the study. Implantable telemetry devices continuously monitored heart rate and blood pressure over 24-hours, and ultrasoundguided kidney biopsies were collected for RNA-Seq. Serum 17 beta-estradiol concentration correlated BP in females. BP in males correlated with $\mathrm{Na}^{+}$intake, blood urea nitrogen, and glucose. Cell type composition of renal biopsies was consistent between females and males. Sex differences were observed in the kidney transcriptomes by principal components analysis and weighted gene coexpression network analysis. Network analysis revealed HNF4A, ESR1, ESR2, SMARCA4, TP53, and $N R 3 C 1$ as $\mathrm{BP}$ regulators in males. Our results demonstrate sex differences in primate kidney molecular networks and provide evidence of a novel link between renal transcription factors and BP regulation in males. Understanding sex differences and transcriptome variation in primate kidneys correlated with BP and clinical measures associated with BP will inform better therapies towards the goal of precision medicine for women and men.

\section{Introduction}

Cardiovascular disease is the leading cause of mortality worldwide. A major risk factor for cardiovascular disease is hypertension (HT), a complex and prevalent disease that affects nearly half of American adults(1). Early detection and diagnosis of HT can be difficult because individuals usually do not display symptoms, and while some cases of HT tied to a specific genetic variant, for the vast majority of cases, there are no clinical measures that predict when an individual will develop HT prior to an observed increase in blood pressure (BP) $(1,2)$. This gap results in patient BP control after $\mathrm{HT}$ diagnosis rather than prevention of BP increase and $\mathrm{HT}(1,3)$. If left untreated, $\mathrm{HT}$ can lead to secondary complications such as prolonged damage to the circulatory and organ systems $(3,4)$. While HT may be the result of single gene deleterious mutations, the majority of the population suffers from a more genetically complex form of the disease with variation in multiple interacting genes, which are influenced by environmental factors.

Both women and men develop HT, and while there is some overlap, sex differences have been frequently observed(1,5-13). For example, sex differences in the Renin Angiotensin Aldosterone System, specifically in androgen and estrogen receptor expression, have been observed in animals and humans $(6,8-11,13)$. Several studies have identified sex-specific single nucleotide polymorphisms associated with $\mathrm{HT}$ and disparities between women and men in pharmacogenetic drug responses to available therapies $(7,14-$ 16). Additionally, women generally have lower BP than men prior to the onset of menopause (16). Despite this evidence, current HT guidelines do not include recommendations for sex-specific treatment 
strategies(1). This is partially due to many studies related to HT being performed using only male subjects or grouping both sexes together for simplicity or technical limitations(17).

Baboons (Papio hamadryas) are genetically and physiologically similar to humans and have been used to study complex heritable human diseases, including HT and sodium-sensitive HT(18-25). Pedigreed, phenotyped and genotyped baboons at the Southwest National Primate Research Center (SNPRC) are a resource for identifying the genetic factors that regulate BP. These baboons are sodium-naïve, unlike the human population, a characteristic essential for understanding BP regulation and initiation of $\mathrm{HT}(18,21,22,24,26-28)$. The similarity of baboons to humans, ability to control environmental exposures, and ability to compare healthy and diseased animals enables investigation of more complex diseases that would not be easily studied in a controlled manner in human populations. These characteristics also allow for direct translation of findings to humans. In addition, recent advances of cell type-specific gene expression in the kidney allow for greater resolution of bulk RNA-Seq comparative studies to explore the underlying genetics of BP regulation(2,29).

We hypothesize there are differences in BP and renal molecular networks in female and male primates. To better understand sex differences, we selected sodium-naïve female and male baboons on a lowsodium chow diet. BP was measured continuously for 24-hours by implantable telemetry device, and transcriptome profiling of kidney cortex biopsies was performed on each animal. Sex differences were observed in clinical measures and the kidney cortex transcriptome. Unbiased analysis by Weighted Gene Co-expression Network Analysis (WGCNA) allowed us to leverage genetic variability in our cohort to identify genes associated with BP variation in males, but not females. We identified HNF4A, ESR1, ESR2, SMARCA4, TP53, and NR3C1 as regulators of BP in males. The high degree of similarity between humans and baboons allows these findings to inform sex differences in BP regulation in humans. There are clear sex differences in a number of BP-related clinical measures as well as the kidney transcriptome, which are important for development of diagnostics and therapies that address this variation in women and men.

\section{Methods}

\section{Ethics, study design, and data collection}

We utilized a cohort of olive baboons (Papio hamadryas; Taxonomy ID 9557) maintained as part of the pedigreed baboon colony at SNPRC, located on the campus of Texas Biomedical Research Institute, San Antonio, Texas. All animal procedures were reviewed and approved by Texas Biomedical Research Institute's Institutional Animal Care and Use Committee (IACUC). SNPRC facilities at the Texas Biomedical Research Institute and animal use programs are accredited by Association for Assessment and Accreditation of Laboratory Animal Care International (AAALAC), operate according to all National Institutes of Health (NIH) and U.S. Department of Agriculture (USDA) guidelines, and are directed by veterinarians (DVM). All animal care decisions were made by the SNPRC veterinarians. Enrichment was provided on a daily basis by the SNPRC veterinary staff and behavioral staff in accordance with AAALAC, 
$\mathrm{NIH}$, and USDA guidelines. Baboons were selected based on family history of $\mathrm{HT}$ as previously described (females: $n=8$, age $17.88 \pm 1.35$ years; males: $n=9$, age $8.10 \pm 2.38$ years). The KINSHIP program from Pedigree Database System (PEDSYS v. 2.0) was used with the Stevens-Boyce algorithm to calculate kinship coefficients to ensure similar degrees of relatedness among females and among males $(30,31)$.

The baboons were raised and maintained on a standard monkey chow diet (high complex carbohydrates; low fat ("Monkey Diet 15\%/5LEO," LabDiet, PMI Nutrition International) prior to study initiation. Animals were acclimated to cages for at least 8 weeks prior to study. Animals had free access to $500 \mathrm{~g}$ chow ad libitum in individual cages during feeding times. Food consumption, $\mathrm{Na}^{+}$intake, body weight, and health status were monitored weekly for each animal throughout the study. In females, $\mathrm{Na}^{+}$intake per $\mathrm{kg}$ animal was calculated as the sum of food $\mathrm{Na}^{+}$intake divided by the animal weight. In males, $\mathrm{Na}^{+}$intake per $\mathrm{kg}$ animal was calculated as the sum of food $\mathrm{Na}^{+}$intake plus $\mathrm{Na}^{+}$in saline infusions, divided by the animal weight. Graphical abstract created with BioRender.com

\section{Telemetry implantation, and kidney biopsy and blood collection}

All animals were preoperatively treated with ketorolac $(5-30 \mathrm{mg})$, sedated with ketamine $(10 \mathrm{mg} / \mathrm{kg}, \mathrm{IM})$, and maintained on isoflurane (1.3-3.0\%) anesthesia throughout telemeter implant, kidney biopsy, and blood collection procedures. Blood was drawn in EDTA tubes and separated into plasma and serum by centrifugation, and kidney cortex biopsies were collected via ultrasound guidance and flash frozen in liquid nitrogen. Animals were monitored during collections and throughout recovery. Postoperative care included observation for swelling at the surgical sight and monitoring until animal was conscious. Buprenorphine $(0.2 \mathrm{mg} / \mathrm{kg}, \mathrm{SQ})$ was administered for post-operative pain relief immediately once animals were awake. Buprenorphine ( $0.2 \mathrm{mg} / \mathrm{kg}, \mathrm{SQ})$ was administered as needed $24-48$ hours after surgery.

\section{Diet, housing, and BP measurements in baboons}

Females were run into individual cages for 4 hours (passing over an electronic weighing scale) for feeding; they were fed a chow diet $\left(17.3 \mathrm{mmol} \mathrm{Na}^{+} / 500 \mathrm{~g}\right.$ food consumed) ad libitum once a day for 6 weeks. Female baboons were housed in an outdoor social group with one vasectomized male (not on study) to provide full social and physical activity. Females were surgically implanted with a PhysioTel Digital implant model M10 (Data Science International (DSI)) under the external abdominal oblique muscle, and the catheter was implanted in the femoral artery to obtain 24-hour continuous BP, heart rate, temperature, and activity measurements in Ponemah software v 6.51 (DSI).

Male baboons were fed a chow diet $\left(20 \mathrm{mmol} \mathrm{Na}^{+} / 500 \mathrm{~g}\right.$ consumed) for 6 weeks and saline infused by intravenous catheter as described by Spradling-Reeves et al(21). Male baboons were tethered in individual cages, and intravenous catheters were surgically implanted as previously described by Carey 
et al. to obtain 24-hour continuous BP, heart rate, temperature, and activity measurements in Ponemah software v 5.2 (DSI)(26).

\section{Clinical measures related to kidney function and BP}

Blood chemistry panels were performed to measure hematocrit, glucose, total protein, blood urea nitrogen (BUN), creatinine, serum $\mathrm{Na}^{+}$, and serum $\mathrm{K}^{+}$as described (21). Sodium outtake, plasma renin activity, plasma aldosterone, and PAH clearance were measured as described (21). The cytokine and chemokines IL-1Ra, IL-2, IL-6, IL-8, IP-10, MCP-1, MIP-1a and SCD40L were measured in plasma using a custom Luminex assay as detailed by Giavedoni(32). Serum 17 beta-estradiol was measured in female baboons with the 17 beta Estradiol ELISA Kit (Abcam); human female serum (age 28 years) was used as a positive control.

\section{Telemetry data analysis}

Ponemah software was used for BP analysis with signal acquired at a logging rate of 10 seconds per minute. Data were reduced to 10-minute periods throughout the study for mean arterial BP (MAP), systolic BP, diastolic BP, and heart rate. The data were calculated for 24-hours, as well as 12-hour daytime (6:00 am-6:00 pm) and 12-hour nighttime intervals (6:00 pm-6:00 am). BP data reported here are based on the last day of recording on chow diet before kidney cortex biopsy collection.

\section{RNA isolation, library preparation, and sequencing}

RNA was isolated from kidney biopsy samples using the Direct-zol RNA Miniprep Plus Kit (Zymo Research). Tissue was homogenized in $600 \mu \mathrm{L}$ of TRI reagent (Zymo Research) using a BeadBeater (Biospec Products) for $3 \times 30 \mathrm{sec}$ with RNA purification according to the Direct-zol RNA Miniprep Plus Kit instructions. RNA was quantified by Qubit RNA BR Assay Kit (Invitrogen), and RNA integrity was determined with an RNA ScreenTape Kit on the TapeStation 2200 system (Agilent). cDNA libraries were prepared using the KAPA Stranded mRNA-Seq Kit (Roche). Libraries were quantified using a KAPA Library Quantification Kit (Roche), and quality was determined with a DNA ScreenTape Kit on the TapeStation 2200 system (Agilent). Sequencing was done using a HiSeq 2500 (Illumina).

\section{RNA-Seq data processing}

Female and male transcripts were processed together in Partek ${ }^{\circledR}$ Flow $^{\circledR}\left(\right.$ Partek $^{\circledR}$, Inc.) with a minimum read length of 25 and minimum Phred 30. Reads were aligned to the olive baboon genome (papAnu2.0; 
March 2012).

Transcripts were annotated to identify kidney-specific cell types as shown by Park et al(2). The full transcript list generated in Partek ${ }^{\circledR}$ Flow $^{\circledR}$ was imported into Partek ${ }^{\circledR}$ Genomics Suite ${ }^{\circledR}$ (Partek ${ }^{\circledR}$, Inc) for principal component analysis (PCA).

\section{Weighted gene co-expression network analysis}

Transcripts were filtered for expression values totaling $<17$ among all samples and filtered based on coefficient of variation for values equal to 0 prior to sex-specific WGCNA. The $R$ package WGCNA was run with default settings which assign each transcript to a single module as described by Langfelder and Horvath(33).

\section{Pathway and network analysis}

Pathway and causal network enrichment analyses of genes in significant modules were performed using Ingenuity Pathway Analysis software (IPA; Ingenuity ® Systems).

Using search terms "hypertension" and "blood pressure", variants were downloaded from the GWAS Catalog and merged with genes in significant WGCNA modules (Galaxy Genome, https://usegalaxy.org/) to identify genes with variants previously associated with BP(34).

\section{Statistics}

\section{Clinical Measures}

Mean values and standard deviations for $\mathrm{Na}^{+}$intake are reported as the average over 5 days prior to biopsy collection. Unpaired t-tests with or without Welch's correction were performed on each of the clinical and BP traits as appropriate. Spearman correlation was performed on each of the clinical and BP traits. Data are expressed as mean, mean $\pm \mathrm{SD}$, or correlation r value, and were considered to be statistically significant if p-value $<0.05$.

\section{Transcripts}

TMM+1 was used for normalization of trimmed and aligned transcripts. Multiple unpaired t-tests with FDR Two-stage setup (Benjamini, Krieger, and Yekutieli) for multiple testing were performed on cell type-specific transcripts between females and males. PCA was performed on normalized transcripts with ellipsoids representative of 2 standard deviations away from the mean. WGCNA was performed using 
Pearson correlation with a $p$-value cutoff $<0.05$. Correlation directionality was calculated by subtracting expression values across transcripts of animals with the lowest BP from animals with the highest BP for transcripts correlated with BP and input into as expression values for IPA network analysis. Upstream analysis and causal network regulator lists were ranked by $p$-value. Data are expressed as mean, mean \pm $\mathrm{SD}$, or correlation r value, and were considered to be statistically significant if $p$-value $<0.05$.

\section{Results}

\section{BP in female and male baboons}

Pedigreed female and male baboons were identified from familial lines with variation in BP, which is potentially related to genetic variation in regulation of BP (Additional file 1 tab S1). Telemetry measurements of MAP, systolic BP, and diastolic BP showed that these are continuous traits among this population of pedigreed baboons for both sexes over 24-hours and day/night intervals. This pattern is represented by the variation exhibited in 24-hour MAP (Figure 1). Sex differences were significant in daytime MAP, daytime systolic BP, 24-hour systolic BP, and nighttime systolic BP between females and males (Additional file 1 tab S2).

\section{Clinical measures in female and male baboons}

Significant differences between female and male baboons were observed in serum $\mathrm{Na}^{+}(\mathrm{p}-$ value $=0.012)$, BUN ( $p$-value $<0.001$ ), and glucose ( $p$-value=0.0018) (Additional file 1 tab S2). BP was significantly different between female and male baboons for 24-hour systolic BP ( $p$-value $<0.0001$ ), daytime MAP ( $p$-value=0.0107), daytime systolic BP ( $p$-value $<0.0001)$, and nighttime systolic BP ( $p$ value $=0.0001$ ) (Additional file 1 tab S2). Serum 17 beta-estradiol concentrations were significantly correlated with 24-hour MAP ( $p$-value=0.0458), nighttime MAP ( $p$-value=0.0458), 24-hour systolic BP ( $p$ value $=0.0279)$, and nighttime systolic $B P(p$-value $=0.0279)$ in females; but there was no significant correlation between BP and age, $\mathrm{Na}^{+}$intake; blood measures of BUN, total protein, glucose, hematocrit; or serum measures of $\mathrm{K}^{+}, \mathrm{Na}^{+}$(Table 2, Additional file 1 tab S3). Males showed negative correlation between 24-hour diastolic BP, daytime diastolic BP, and nighttime diastolic BP with $\mathrm{Na}^{+}$intake ( $\mathrm{p}$-values $=0.0143,0.0112,0.0239$ ). Plasma IP-10 was positively correlated with BUN ( $p$-values $=0.047)$; and a positive correlation between nighttime systolic BP and glucose ( $p$-value $=0.0313$ ) was observed (Table 2, Additional file 1 tab S3). Males also demonstrated 24-hour MAP and nighttime MAP, negatively correlated with PAH clearance ( $p$-value $=0.014,0.021$ ). 24-hour MAP, 24-hour diastolic BP, daytime diastolic BP, and nighttime diastolic BP negatively correlated with plasma IL-8. Plasma IL-8 was also negatively correlated with plasma IL-6 ( $p$-value $=0.006$ ).

\section{Cell type-specific gene expression in kidney cortex biopsies}


Transcript quality was similar between female and male samples, but females had a lower average transcript alignment and greater average read lengths than males (Additional file 1 tab S4). All samples met quality standards (total reads, alignment, coverage, read length, depth, read quality) to proceed with downstream analysis (Additional file 1 tab S4). Kidney cortex RNA-Seq (Additional file 1 tab S5) data showed representation of all kidney cell types previously characterized by Park et al (Additional file 1 tab S6)(2). Thick ascending limb and proximal tubules had the greatest expression among all samples, suggesting these may be the predominant cell types within the kidney cortex (Additional file 1 tab S6). Abundance of kidney-specific genes $(n=40)$ did not differ significantly between females and males (Figure 2A, Additional file 1 tab S7), indicating consistency of biopsy collection among study animals.

\section{Sex differences in kidney cortex transcriptome}

Although kidney cortex-specific genes did not differ between females and males, PCA of all transcripts for females and males revealed the top principal components of $24 \%, 11.6 \%$, and $9.03 \%$, which account for $44.6 \%$ variation in the samples and demonstrate two clusters with sex-specific profiles (Figure 2B). Coefficient of variation for transcripts in females and males demonstrated sex differences in variation in gene expression and also revealed sex differences in distribution of variation in the transcriptome (Figure 2C, Additional file 1 tab S8).

\section{Relation of kidney transcriptome to BP-related clinical measures}

Each WGCNA module contained transcripts co-correlated with each other, the resulting modules were then tested for correlation with each quantitative trait, e.g., daytime systolic BP, blood glucose, etc. (Figure 3 , Additional file 2, Additional file 1 tab S9, S10). No modules were significantly correlated with BP traits in females (Additional file 2, Figure 1). Analysis of males revealed 3 modules (greenyellow, $n=750$ transcripts; yellow, $n=1311$ transcripts; magenta, $n=915$ transcripts) were positively correlated with $B P$ traits: nighttime MAP, 24-hour systolic BP, nighttime systolic BP, 24-hour diastolic BP, nighttime diastolic $\mathrm{BP}(\mathrm{p}$-values $=0.02,0.03,0.03 ; 0.05,0.01,0.04$, respectively) (Figure 3$)$. These modules contained 42 renal-specific genes and 237 genes with GWAS variants associated with BP (Additional file 1 tab S10).

\section{Gene networks in male kidney cortex biopsies}

In males, upstream regulators and master regulators HNF4A, ESR1, ESR2, SMARCA4, TP53, $N R 3 C 1$ were the most significant with the greatest number of downstream targets for genes in modules correlated with BP (pink, greenyellow, magenta, and yellow) (Figure 4, Additional file 1 tab S11, S12). Network analysis of HNF4A, ESR1, ESR2, SMARCA4, TP53, and NR3C1 demonstrated they had overlapping direct connections forming a single gene network (Figure 3). Proximal tubule cells were 
identified as an important cell type in these networks, with the cell type-specific expression of HNF4A. Predicted upstream regulators included 4 kidney cell types (proximal (general)-HNF4A, inner medullaELF5, podocyte-WT1, and plasma cell-IRF4) in the network and included ESR1 among 14 genes with GWAS associations as upstream regulators in modules correlated with BP in males (Figure 4, Additional file 1 tab S11). Furthermore, targets of these upstream activators and inhibitors included cell membranelocalized potassium and calcium ion channels, as well as targets related to proliferation and tissue remodeling (Additional file 1 tab S11, S12).

\section{Discussion}

HT impacts approximately $50 \%$ of the US adult population(1). Currently, there are no sex-specific diagnostics or treatment guidelines, despite numerous studies in humans and rodents showing sex differences in previously identified regulators of HT. It is well-known that HT is a complex disease with many players in many tissues contributing to the overall molecular mechanisms underlying BP regulation. The baboon has been used as a model for HT due to the genetic and physiological similarity to humans(18-25). Previous studies have focused on male baboons; therefore, sex differences in kidney gene networks underlying BP regulation have not been assessed in primates, including humans and baboons(18-25). In this study, we investigated sex differences in kidney gene networks associated with $\mathrm{BP}$ and BP-related clinical measures in female and male baboons to nominate regulatory networks central to BP regulation. Establishing whether there are sex differences in kidney gene networks associated with BP and BP-related traits is essential for developing more effective diagnostics and therapies for both women and men.

A major finding of this study was that BP differences between females and males varied by measurement type and time of day. Sex differences were observed in 24-hour systolic BP, daytime MAP, nighttime diastolic BP, and nighttime systolic BP, with females having lower BP than males. Females demonstrated correlation between serum 17 beta-estradiol concentration and 24-hour MAP, nighttime MAP, 24-hour systolic BP, and nighttime systolic BP but no other clinical measures. The role of 17 betaestradiol in female primate BP regulation still needs further investigation. BP correlated with a number of clinical measures in males: 24-hour diastolic BP, daytime diastolic BP, and nighttime diastolic BP with $\mathrm{Na}^{+}$ intake; 24-hour MAP, daytime MAP, and 24-hour systolic BP with BUN; as well as nighttime systolic BP with glucose. We also observed 24-hour MAP and nighttime MAP, negatively correlated with PAH clearance. 24-hour MAP, 24-hour diastolic BP, daytime diastolic BP, and nighttime diastolic BP negatively correlated with plasma IL-8. Daytime diastolic BP was positively correlated with plasma IL-6. Interestingly, plasma renin activity and plasma aldosterone did not correlate with any BP measures. This provides evidence that these typical BP-related clinical measures are not as informative for females as for males, and emphasizes the importance of sex-specific markers of HT pathology and treatment plans.

We demonstrated consistency in kidney biopsies by cell composition, diet, as well as both time of day and duration of collection of telemetry data between females and males - all indicating that differences in the study design did not account for kidney transcriptome differences. In addition, we showed sex 
differences in the primate kidney transcriptome(2,35-37). WGCNA of kidney cortex RNA-Seq data was used as an unbiased approach to identify sex-specific transcripts correlated with BP. This analysis is the most appropriate considering the clear variability observed in the BP and transcriptome data, and adds statistical power that would be lost by binning for pairwise comparison. Our analysis did not reveal any WGCNA transcript modules correlated with BP in females, demonstrating there may be other important players for female BP regulation not found in kidneys with a low sodium dietary environment. WGCNA of males revealed 4 transcript modules strongly correlated with BP, further supporting the observed sex differences in gene expression.

Unlike the females, identification of significant WGCNA modules in males correlated with BP allowed us to move forward with the dataset and perform network analysis. In males, gene modules positively correlated with BP contained overlapping networks with predicted regulation by ESR1, HNF4A, and TP53 which have been previously identified as important players related to BP regulation in the kidney $(38,39)$. While some of these players have been associated with the RAAS, neither BP or the kidney cortex transcriptome correlated with plasma renin or aldosterone levels $(38,39)$. Indicating BP regulation in the kidney is not entirely driven by the RAAS.

However, expression of ESR1, HNF4A, and TP53 did not directly correlate with BP. Activity of these gene products is known to be dependent on post-translational modifications, i.e. gene expression does not directly inform their protein activity. These findings indicate the need to verify the roles of these master regulators for BP regulation with assessment of post-translational modifications and their impact on these regulatory networks(41-44).

Network analysis of renal transcripts in male modules correlated with BP identified several genes and upstream regulators related to maintenance of ion channels (e.g., CLCN3, KCNK3, CLIC3, KCNMA1), insulin regulation (TCF7L2, inhibited), and transcription factor HNF4A (predicted activated) which is exclusively expressed in the proximal tubules and involved in regulating transport proteins(45-54). We also found estrogen and glucocorticoid receptors (ESR1, predicted activated; ESR2, predicted inhibited; $N R 3 C 1$, inhibited) as upstream regulators of genes in modules correlated with $\mathrm{BP}$, which influence the reabsorption of calcium, potassium, sodium, and glucose in the kidney $(37,46-48,53,55)$. Inclusion of these genes in BP correlated modules connects hormone receptors, sodium management and glucose homeostasis with BP regulation at the molecular level in males. TCF7L2 and ESR1 in our results were previously shown by GWAS to have variants associated with BP. Due to sample limitations, we were unable to further investigate the role of estrogens in male BP regulation. Lastly, we identified upstream regulators of transcripts related to cell proliferation and chromatin remodeling (TP53, predicted activated; SMARCA4, inhibited; NOTCH1) in modules correlated with $\mathrm{BP}(56-58)$. The cross talk between ion and glucose homeostasis suggests male primates with higher BP in a low sodium dietary environment have a lower capability to remodel their vasculature, possibly leading to less flexibility and increased arterial stiffness in response to damage and stress compared to animals with lower BP. 
This is the first study to characterize the kidney cortex transcriptome of adult female baboons, allowing comparison with males, and the first to nominate renal networks that influence BP regulation in females. Furthermore, this work provides evidence for the importance of including female subjects in research to understand differences in BP regulation. Follow-up studies to validate mechanisms of regulatory networks are needed for translation of findings to understanding regulation of BP in women.

Study Limitations: For this comparison, there were a few differences in the study design for females versus males. Males were housed in individual cages and females were housed in a social group. Housing differences were due to limitations of telemetry transmitter distances when the study of male baboons was conducted; whereas, newer telemetry technology used for the females allowed collection of data from animals in social groups. In both studies, animals were acclimated to housing and social groups (males had visual contact with all other males in the study) for a minimum of 2 weeks with BP monitored for stability prior to study initiation. Although study design differed slightly with male sodium intake via saline solution, no studies to date indicate route of administration of sodium impacts BP or other BP regulating players. The females in this study were premenopausal based on age, menstrual cycles, and 17 beta-estradiol levels. If age were a factor influencing BP, we would expect females to have higher BP than males, as seen when comparing older versus younger humans, which is contrary to our study results. While we cannot entirely eliminate the possibility that age differences influenced our results, we show that different mechanisms underly renal BP regulation in older adult females compared with middle aged adult males. Even with these limitations, our findings support the need to further understand sex-differences in renal molecular mechanisms influencing BP.

\section{Declarations}

\section{Ethics approval and consent to participate}

Details on ethics for animal use in this study are detailed in the section "ethics, study design, and data collection"

\section{Consent for publication}

Not applicable

\section{Availability of data and materials}

The datasets generated and/or analyzed during the current study are available in the locations detailed below:

RNA-Seq dataset: NCBI GEO GSE166295.

GWAS data were derived from: GWAS Catalog; https://www.ebi.ac.uk/gwas/ (34)

Cell type specific gene identifiers were derived from Park et al(2). 


\section{Competing interests}

None

\section{Funding}

This investigation was conducted in facilities constructed with support from Research Facilities Improvement Program Grant Numbers C06 RR015456 and C06 RR013556 from the National Center for Research Resources (NCRR), National Institutes of Health $(\mathrm{NIH})$. Other resources used in this study were supported by NIH grant 5 R01 HL68180, SNPRC grant P51 OD011133 from the Office of Research Infrastructure Programs (ORIP), NIH.

\section{Acknowledgements}

None

\section{References}

1. Whelton PK, Carey RM, Aronow WS, Casey Jr. DE, Collins KJ, Dennison Himmelfarb C, et al. 2017 ACC/AHA/AAPA/ABC/ACPM/AGS/APhA/ASH/ASPC/NMA/PCNA Guideline for the Prevention, Detection, Evaluation, and Management of High Blood Pressure in Adults: A Report of the American College of Cardiology/American Heart Association Task Force on Clinical Pr. Hypertension [Internet]. 2017/11/15. 2018;71(6):e13-115. Available from: https://www.ncbi.nlm.nih.gov/pubmed/29133356

2. Park J, Shrestha R, Qiu C, Kondo A, Huang S, Werth M, et al. Single-cell transcriptomics of the mouse kidney reveals potential cellular targets of kidney disease. Science (80-) [Internet]. 2018/04/07. 2018;360(6390):758-63. Available from: https://www.ncbi.nlm.nih.gov/pubmed/29622724

3. Virani SS, Alonso A, Benjamin EJ, Bittencourt MS, Callaway CW, Carson AP, et al. Heart Disease and Stroke Statistics-2020 Update: A Report From the American Heart Association. Circulation [Internet]. 2020/01/30. 2020;141(9):e139-596. Available from: https://www.ncbi.nlm.nih.gov/pubmed/31992061

4. Sun Z. Aging, arterial stiffness, and hypertension. Hypertension [Internet]. 2014/11/05. 2015;65(2):252-6. Available from: https://www.ncbi.nlm.nih.gov/pubmed/25368028

5. Ojeda NB, Intapad S, Alexander BT. Sex differences in the developmental programming of hypertension. Acta Physiol [Internet]. 2013/11/26. 2014;210(2):307-16. Available from: https://www.ncbi.nlm.nih.gov/pubmed/24268043

6. Hutson DD, Gurrala R, Ogola BO, Zimmerman MA, Mostany R, Satou R, et al. Estrogen receptor profiles across tissues from male and female Rattus norvegicus. Biol Sex Differ [Internet]. 2019/01/13. 2019;10(1):4. Available from: https://www.ncbi.nlm.nih.gov/pubmed/30635056 
7. Wang J, Jiang W, Sharma M, Wu Y, Li J, You N, et al. Sex differences in antihypertensive drug use and blood pressure control. Postgr Med J [Internet]. 2019/06/07. 2019;95(1124):295-9. Available from: https://www.ncbi.nlm.nih.gov/pubmed/31171709

8. Garovic VD, August P. Sex Differences and Renal Protection: Keeping in Touch with Your Feminine Side. J Am Soc Nephrol [Internet]. 2016/05/18. 2016;27(10):2921-4. Available from:

https://www.ncbi.nlm.nih.gov/pubmed/27188841

9. Boese AC, Kim SC, Yin KJ, Lee JP, Hamblin MH. Sex differences in vascular physiology and pathophysiology: estrogen and androgen signaling in health and disease. Am J Physiol Hear Circ Physiol [Internet]. 2017/06/20. 2017;313(3):H524-45. Available from:

https://www.ncbi.nlm.nih.gov/pubmed/28626075

10. Sharma PK, Thakur MK. Estrogen receptor a expression in mice kidney shows sex differences during aging. Biogerontology. 2004;5(6):375-81.

11. Lane PH. Estrogen receptors in the kidney: Lessons from genetically altered mice. Gend Med. 2008;5(SUPPL. 1).

12. Kwekel JC, Desai VG, Moland CL, Vijay V, Fuscoe JC. Sex differences in kidney gene expression during the life cycle of F344 rats. Biol Sex Differ. 2013;4(1).

13. Esqueda MED, Craig T, Hinojosa-Laborde C. Effect of ovariectomy on renal estrogen receptor-a and estrogen receptor- $\beta$ in young salt-sensitive and -resistant rats. Hypertension. 2007;50(4):768-72.

14. Ljungman C, Kahan T, Schioler L, Hjerpe P, Hasselstrom J, Wettermark B, et al. Gender differences in antihypertensive drug treatment: results from the Swedish Primary Care Cardiovascular Database (SPCCD). J Am Soc Hypertens [Internet]. 2014/12/11. 2014;8(12):882-90. Available from:

https://www.ncbi.nlm.nih.gov/pubmed/25492831

15. Kajinami K, Brousseau ME, Ordovas JM, Schaefer EJ. Polymorphisms in the multidrug resistance-1 (MDR1) gene influence the response to atorvastatin treatment in a gender-specific manner. Am J Cardiol [Internet]. 2004/04/15. 2004;93(8):1046-50. Available from:

https://www.ncbi.nlm.nih.gov/pubmed/15081455

16. Peters SAE, Muntner P, Woodward M. Sex Differences in the Prevalence of, and Trends in, Cardiovascular Risk Factors, Treatment, and Control in the United States, 2001 to 2016. Circulation [Internet]. 2019/02/20. 2019;139(8):1025-35. Available from:

https://www.ncbi.nlm.nih.gov/pubmed/30779652

17. Maric-Bilkan C, Galis ZS. Trends in NHLBI-Funded Research on Sex Differences in Hypertension. Circ Res [Internet]. 2016/08/20. 2016;119(5):591-5. Available from:

https://www.ncbi.nlm.nih.gov/pubmed/27539972

Page 13/23 
18. Cox LA, Comuzzie AG, Havill LM, Karere GM, Spradling KD, Mahaney MC, et al. Baboons as a model to study genetics and epigenetics of human disease. ILAR J [Internet]. 2013/11/01. 2013;54(2):106-21. Available from: https://www.ncbi.nlm.nih.gov/pubmed/24174436

19. Spradling KD, Glenn JP, Garcia R, Shade RE, Cox LA. The baboon kidney transcriptome: analysis of transcript sequence, splice variants, and abundance. PLoS One [Internet]. 2013/05/03. 2013;8(4):e57563. Available from: https://www.ncbi.nlm.nih.gov/pubmed/23637735

20. Northcott CA, Glenn JP, Shade RE, Kammerer CM, Hinojosa-Laborde C, Fink GD, et al. A custom rat and baboon hypertension gene array to compare experimental models. Exp Biol Med [Internet]. 2012/01/10. 2012;237(1):99-110. Available from: https://www.ncbi.nlm.nih.gov/pubmed/22228705

21. Spradling-Reeves KD, Shade RE, Haywood JR, Cox LA. Primate response to angiotensin infusion and high sodium intake differ by sodium lithium countertransport phenotype. J Am Soc Hypertens [Internet]. 2017/02/28. 2017;11(3):178-84. Available from: https://www.ncbi.nlm.nih.gov/pubmed/28238630

22. Kammerer CM, Cox LA, Mahaney MC, Rogers J, Shade RE. Sodium-lithium countertransport activity is linked to chromosome 5 in baboons. Hypertension [Internet]. 2001/03/07. 2001;37(2 Pt 2):398-402. Available from: https://www.ncbi.nlm.nih.gov/pubmed/11230307

23. Yeung KR, Chiu CL, Pears S, Heffernan SJ, Makris A, Hennessy A, et al. A Cross-Sectional Study of Ageing and Cardiovascular Function over the Baboon Lifespan. PLoS One [Internet]. 2016/07/20. 2016;11(7):e0159576. Available from: https://www.ncbi.nlm.nih.gov/pubmed/27427971

24. McMahan CA, Wigodsky HS, Moore GT. Direct and indirect blood pressure measurements in baboons. J Appl Physiol [Internet]. 1976/11/01. 1976;41(5 Pt. 1):806-9. Available from: https://www.ncbi.nlm.nih.gov/pubmed/825507

25. Martin LJ, Carey KD, Comuzzie AG. Variation in menstrual cycle length and cessation of menstruation in captive raised baboons. Mech Ageing Dev [Internet]. 2003/09/23. 2003;124(8-9):86571. Available from: https://www.ncbi.nlm.nih.gov/pubmed/14499490

26. Carey D, Kammerer CM, Shade RE, Rice KS, McGill Jr. HC. Selective breeding to develop lines of baboons with high and low blood pressure. Hypertension [Internet]. 1993/06/01. 1993;21(6 Pt 2):1076-9. Available from: https://www.ncbi.nlm.nih.gov/pubmed/8505095

27. Kammerer CM. Effects of sex, age, weight, and heredity on blood pressure in baboons. Am J Hum Biol [Internet]. 1995/01/01. 1995;7(2):149-58. Available from:

https://www.ncbi.nlm.nih.gov/pubmed/28557219

28. Rogers J, Mahaney MC, Witte SM, Nair S, Newman D, Wedel S, et al. A genetic linkage map of the baboon (Papio hamadryas) genome based on human microsatellite polymorphisms. Genomics [Internet]. 2000/08/11. 2000;67(3):237-47. Available from: https://www.ncbi.nlm.nih.gov/pubmed/10936045 
29. Clark JZ, Chen L, Chou CL, Jung HJ, Lee JW, Knepper MA. Representation and relative abundance of cell-type selective markers in whole-kidney RNA-Seq data. Kidney Int. 2019;95(4):787-96.

30. Boyce DE, Chon KS, Lee YJ, Lin KT, LeBlanc LJ. Implementation and Computational Issues for Combined Models of Location, Destination, Mode, and Route Choice. Environ Plan A Econ Sp. 1983;15(9):1219-30.

31. B. D. A pedigree data management system. 2.0 edn. Population Genetics Laboratory [Internet]. Google Scholar: Department of Genetics, Southwest Foundation for Biomedical Research; San Antonio; 1996. Available from: https://bio.tools/pedsys

32. Giavedoni LD. Simultaneous detection of multiple cytokines and chemokines from nonhuman primates using luminex technology. J Immunol Methods [Internet]. 2005 Jun;301(1-2):89-101. Available from: https://linkinghub.elsevier.com/retrieve/pii/S0022175905000931

33. Langfelder P, Horvath S. WGCNA: an R package for weighted correlation network analysis. BMC Bioinformatics [Internet]. 2008/12/31. 2008;9:559. Available from:

https://www.ncbi.nlm.nih.gov/pubmed/19114008

34. Buniello A, MacArthur JAL, Cerezo M, Harris LW, Hayhurst J, Malangone C, et al. The NHGRI-EBI GWAS Catalog of published genome-wide association studies, targeted arrays and summary statistics 2019. Nucleic Acids Res [Internet]. 2018/11/18. 2019;47(D1):D1005-12. Available from: https://www.ncbi.nlm.nih.gov/pubmed/30445434

35. Swanson EA, Nelson JW, Jeng S, Erspamer KJ, Yang CL, McWeeney S, et al. Salt-sensitive transcriptome of isolated kidney distal tubule cells. Physiol Genomics [Internet]. 2019/03/16. 2019;51(4):125-35. Available from: https://www.ncbi.nlm.nih.gov/pubmed/30875275

36. Lake BB, Chen S, Hoshi M, Plongthongkum N, Salamon D, Knoten A, et al. A single-nucleus RNAsequencing pipeline to decipher the molecular anatomy and pathophysiology of human kidneys. Nat Commun [Internet]. 2019/06/30. 2019;10(1):2832. Available from: https://www.ncbi.nlm.nih.gov/pubmed/31249312

37. Barry DM, McMillan EA, Kunar B, Lis R, Zhang T, Lu T, et al. Molecular determinants of nephron vascular specialization in the kidney. Nat Commun [Internet]. 2019/12/15. 2019;10(1):5705. Available from: https://www.ncbi.nlm.nih.gov/pubmed/31836710

38. Tremblay AM, Dufour CR, Ghahremani M, Reudelhuber TL, Giguère V. Physiological genomics identifies estrogen-related receptor $a$ as a regulator of renal sodium and potassium homeostasis and the renin-angiotensin pathway. Mol Endocrinol. 2010;24(1):22-32.

39. Buemi M, Marino D, Floccari F, Ruello A, Nostro L, Aloisi C, et al. Effect of interleukin 8 and ICAM-1 on calcium-dependent outflow of $\mathrm{K}+$ in erythrocytes from subjects with essential hypertension. Curr Med 
Res Opin [Internet]. 2004 Jan 22;20(1):19-24. Available from:

https://www.tandfonline.com/doi/full/10.1185/030079903125002720

40. Lu K-T, Keen HL, Weatherford ET, Sequeira-Lopez MLS, Gomez RA, Sigmund CD. Estrogen Receptor a Is Required for Maintaining Baseline Renin Expression. Hypertension [Internet]. 2016 May;67(5):992-9. Available from: https://www.ahajournals.org/doi/10.1161/HYPERTENSIONAHA.115.07082

41. Lung DK, Warrick JW, Hematti P, Callander NS, Mark CJ, Miyamoto S, et al. Bone Marrow Stromal Cells Transcriptionally Repress ESR1 but Cannot Overcome Constitutive ESR1 Mutant Activity. Endocrinology [Internet]. 2019/09/11. 2019;160(10):2427-40. Available from: https://www.ncbi.nlm.nih.gov/pubmed/31504407

42. Anda-Jáuregui G de, Espinal-Enríquez J, Sandoval-Motta S, Hernández-Lemus E. A Boolean Network Approach to Estrogen Transcriptional Regulation. Complexity. 2019;2019:1-10.

43. Yokoyama A, Katsura S, Ito R, Hashiba W, Sekine H, Fujiki R, et al. Multiple post-translational modifications in hepatocyte nuclear factor 4alpha. Biochem Biophys Res Commun [Internet]. 2011/06/29. 2011;410(4):749-53. Available from: https://www.ncbi.nlm.nih.gov/pubmed/21708125

44. Chen WJ, Wang WT, Tsai TY, Li HK, Lee YHW. DDX3 localizes to the centrosome and prevents multipolar mitosis by epigenetically and translationally modulating p53 expression. Sci Rep. 2017;7(1).

45. Gururaja Rao S, Ponnalagu D, Patel NJ, Singh H. Three Decades of Chloride Intracellular Channel Proteins: From Organelle to Organ Physiology. Curr Protoc Pharmacol [Internet]. 2018/07/25. 2018;80(1):11 21 1-11 21 17. Available from: https://www.ncbi.nlm.nih.gov/pubmed/30040212

46. Marable SS, Chung E, Park JS. Hnf4a Is Required for the Development of Cdh6-Expressing Progenitors into Proximal Tubules in the Mouse Kidney. J Am Soc Nephrol [Internet]. 2020/08/09. 2020;31(11):2543-58. Available from: https://www.ncbi.nlm.nih.gov/pubmed/32764140

47. Jung J, Barrett PQ, Eckert GJ, Edenberg HJ, Xuei X, Tu W, et al. Variations in the potassium channel genes KCNK3 and KCNK9 in relation to blood pressure and aldosterone production: an exploratory study. J Clin Endocrinol Metab [Internet]. 2012/08/16. 2012;97(11):E2160-7. Available from: https://www.ncbi.nlm.nih.gov/pubmed/22893713

48. Lambert M, Boet A, Rucker-Martin C, Mendes-Ferreira P, Capuano V, Hatem S, et al. Loss of KCNK3 is a hallmark of RV hypertrophy/dysfunction associated with pulmonary hypertension. Cardiovasc Res [Internet]. 2018/01/24. 2018;114(6):880-93. Available from:

https://www.ncbi.nlm.nih.gov/pubmed/29360952

49. Cheng J, Mao L, Wen J, Li PY, Wang N, Tan XQ, et al. Different Effects of Hypertension and Age on the Function of Large Conductance Calcium- and Voltage-Activated Potassium Channels in Human Mesentery Artery Smooth Muscle Cells. J Am Heart Assoc. 2016;5(9). 
50. Bonnet F, Roussel R, Natali A, Cauchi S, Petrie J, Laville M, et al. Parental history of type 2 diabetes, TCF7L2 variant and lower insulin secretion are associated with incident hypertension. Data from the DESIR and RISC cohorts. Diabetologia [Internet]. 2013/08/15. 2013;56(11):2414-23. Available from: https://www.ncbi.nlm.nih.gov/pubmed/23942764

51. Peng M. Network Pharmacology Analysis Uncovers the Potential Anti-Hypertensive Mechanisms of Xia Sang Ju Granule. J Explor Res Pharmacol. 2020;000(000):1-10.

52. Rizvi S, Raza ST, Rahman Q, Mahdi F. Role of GNB3, NET, KCNJ11, TCF7L2 and GRL genes single nucleotide polymorphism in the risk prediction of type 2 diabetes mellitus. 3 Biotech [Internet]. 2016/01/01. 2016;6(2):255. Available from: https://www.ncbi.nlm.nih.gov/pubmed/28330327

53. Sabbatini AR, Kararigas G. Estrogen-related mechanisms in sex differences of hypertension and target organ damage. Biol Sex Differ [Internet]. 2020/06/04. 2020;11(1):31. Available from: https://www.ncbi.nlm.nih.gov/pubmed/32487164

54. Hunter RW, Ivy JR, Bailey MA. Glucocorticoids and renal Na+transport: implications for hypertension and salt sensitivity. J Physiol [Internet]. 2014/02/19. 2014;592(8):1731-44. Available from: https://www.ncbi.nlm.nih.gov/pubmed/24535442

55. Cheng J, Mao L, Wen J, Li PY, Wang N, Tan XQ, et al. Different Effects of Hypertension and Age on the Function of Large Conductance Calcium- and Voltage-Activated Potassium Channels in Human Mesentery Artery Smooth Muscle Cells. J Am Hear Assoc [Internet]. 2016/09/16. 2016;5(9). Available from: https://www.ncbi.nlm.nih.gov/pubmed/27628569

56. Mukherjee M, Fogarty E, Janga M, Surendran K. Notch Signaling in Kidney Development, Maintenance, and Disease. Biomolecules [Internet]. 2019/11/07. 2019;9(11). Available from: https://www.ncbi.nlm.nih.gov/pubmed/31690016

57. Guerrero-Martinez JA, Reyes JC. High expression of SMARCA4 or SMARCA2 is frequently associated with an opposite prognosis in cancer. Sci Rep [Internet]. 2018/02/03. 2018;8(1):2043. Available from: https://www.ncbi.nlm.nih.gov/pubmed/29391527

58. Peng J, Li X, Zhang D, Chen JK, Su Y, Smith SB, et al. Hyperglycemia, p53, and mitochondrial pathway of apoptosis are involved in the susceptibility of diabetic models to ischemic acute kidney injury. Kidney Int [Internet]. 2014/06/26. 2015;87(1):137-50. Available from: https://www.ncbi.nlm.nih.gov/pubmed/24963915

\section{Tables}

\section{Clinical measures in female and male baboons}




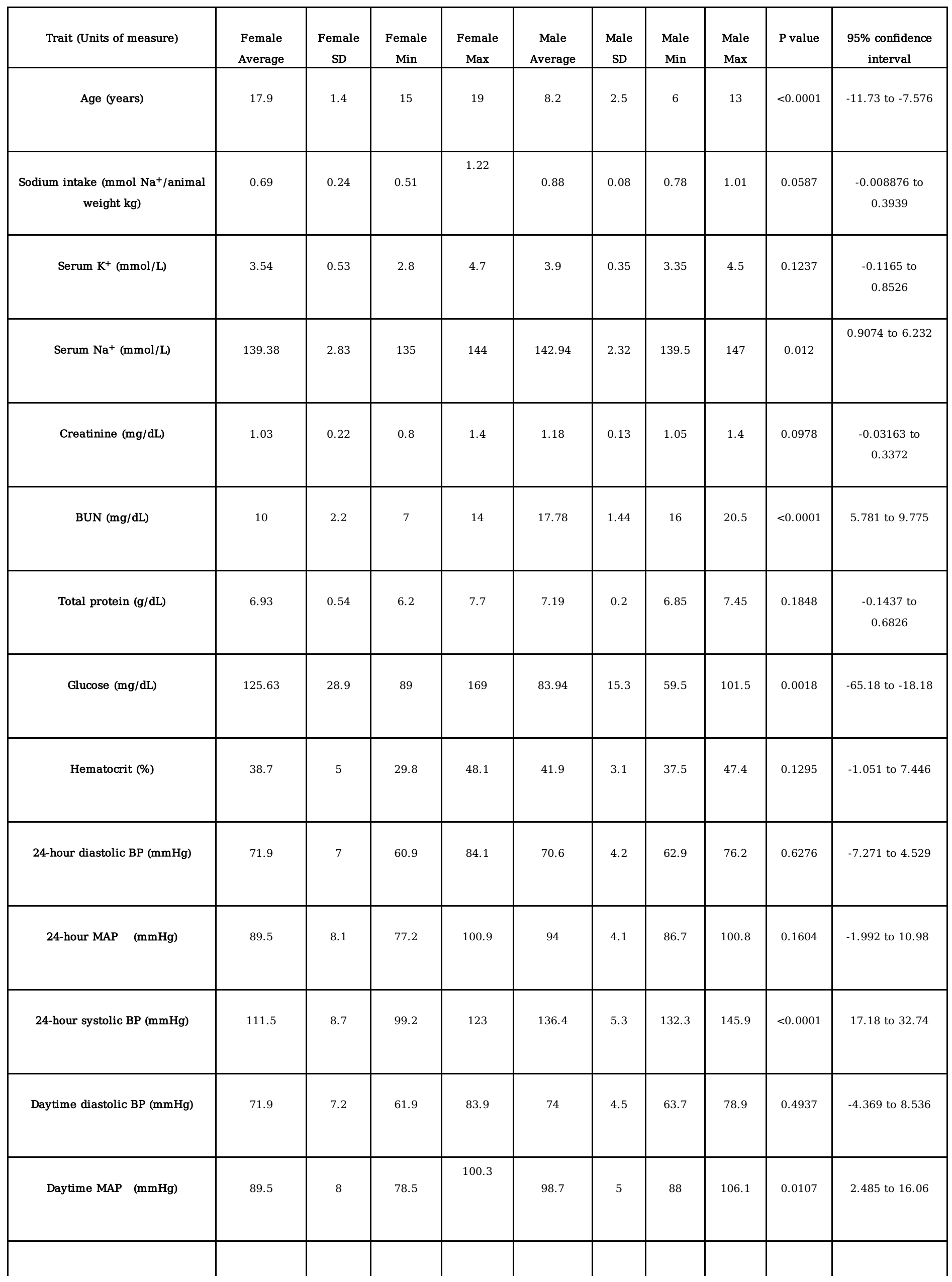




\begin{tabular}{|c|c|c|c|c|c|c|c|c|c|c|}
\hline Daytime systolic BP (mmHg) & 111.7 & 8.5 & 101 & 122.4 & 142.5 & 6 & 135 & 150.8 & $<0.0001$ & 23.25 to 38.27 \\
\hline Nighttime diastolic BP (mmHg) & 71.9 & 7.2 & 60.2 & 84.2 & 68.3 & 4.5 & 62 & 75.9 & 0.2193 & -9.818 to 2.443 \\
\hline Nighttime MAP (mmHg) & 89.5 & 8.4 & 76.3 & 101.3 & 90.8 & 4.2 & 85.3 & 97.5 & 0.6823 & -5.430 to 8.075 \\
\hline Nighttime systolic BP (mmHg) & 111.3 & 9.2 & 98.1 & 123.5 & 132.4 & 5.9 & 126.6 & 142.8 & 0.0001 & 12.76 to 29.34 \\
\hline
\end{tabular}

Table 1. Clinical measures in female and male baboons. Unpaired two-tailed t-tests or unpaired two-tailed t-tests with Welch's correction were performed on each clinical trait in female and male baboons. $\mathrm{P}$ values represent the difference between sexes and were considered significant if less than or equal to 0.05 .

\section{Correlations between clinical measures in female and male baboons}

\begin{tabular}{|c|c|c|c|c|c|}
\hline & & \multicolumn{2}{|c|}{ Female } & \multicolumn{2}{|c|}{ Male } \\
\hline \multicolumn{2}{|c|}{ Correlation variables } & $\mathbf{r}$ & p-value & $\mathbf{r}$ & p-value \\
\hline 17 beta-estradiol & Serum $\mathrm{K}^{+}$ & 0.86 & 0.009 & - & - \\
\hline 17 beta-estradiol & 24-Hour MAP & 0.74 & 0.046 & - & - \\
\hline 17 beta-estradiol & Nighttime MAP & 0.74 & 0.046 & - & - \\
\hline 17 beta-estradiol & 24-Hour systolic BP & 0.79 & 0.028 & - & - \\
\hline 17 beta-estradiol & Nighttime systolic BP & 0.79 & 0.028 & - & - \\
\hline $\mathrm{Na}^{+}$intake & Serum $\mathrm{Na}^{+}$ & -0.67 & 0.076 & 0.88 & 0.003 \\
\hline $\mathrm{Na}^{+}$intake & 24Hour diastolic BP & -0.06 & 0.897 & -0.79 & 0.014 \\
\hline $\mathrm{Na}^{+}$intake & Daytime diastolic BP & -0.04 & 0.943 & -0.81 & 0.011 \\
\hline $\mathrm{Na}^{+}$intake & Nighttime diastolic BP & -0.06 & 0.897 & -0.75 & 0.024 \\
\hline Creatinine & Age & 0.05 & 0.909 & 0.87 & 0.003 \\
\hline BUN & Serum $\mathrm{K}^{+}$ & 0.02 & 0.960 & -0.77 & 0.018 \\
\hline BUN & 24-Hour MAP & -0.10 & 0.830 & -0.70 & 0.043 \\
\hline BUN & Daytime MAP & -0.12 & 0.793 & -0.76 & 0.023 \\
\hline BUN & 24-Hour systolic BP & 0.00 & 1.000 & -0.76 & 0.023 \\
\hline Glucose & Nighttime systolic BP & -0.26 & 0.536 & 0.73 & 0.031 \\
\hline
\end{tabular}

Table 2. Correlations between clinical measures in female and male baboons. Correlation variables are listed between clinical measures for each comparison. Spearman $\mathrm{r}$ values and $\mathrm{p}$-values are presented for female $(\mathrm{N}=8)$ and male baboons $(\mathrm{N}=9)$. 
Figures

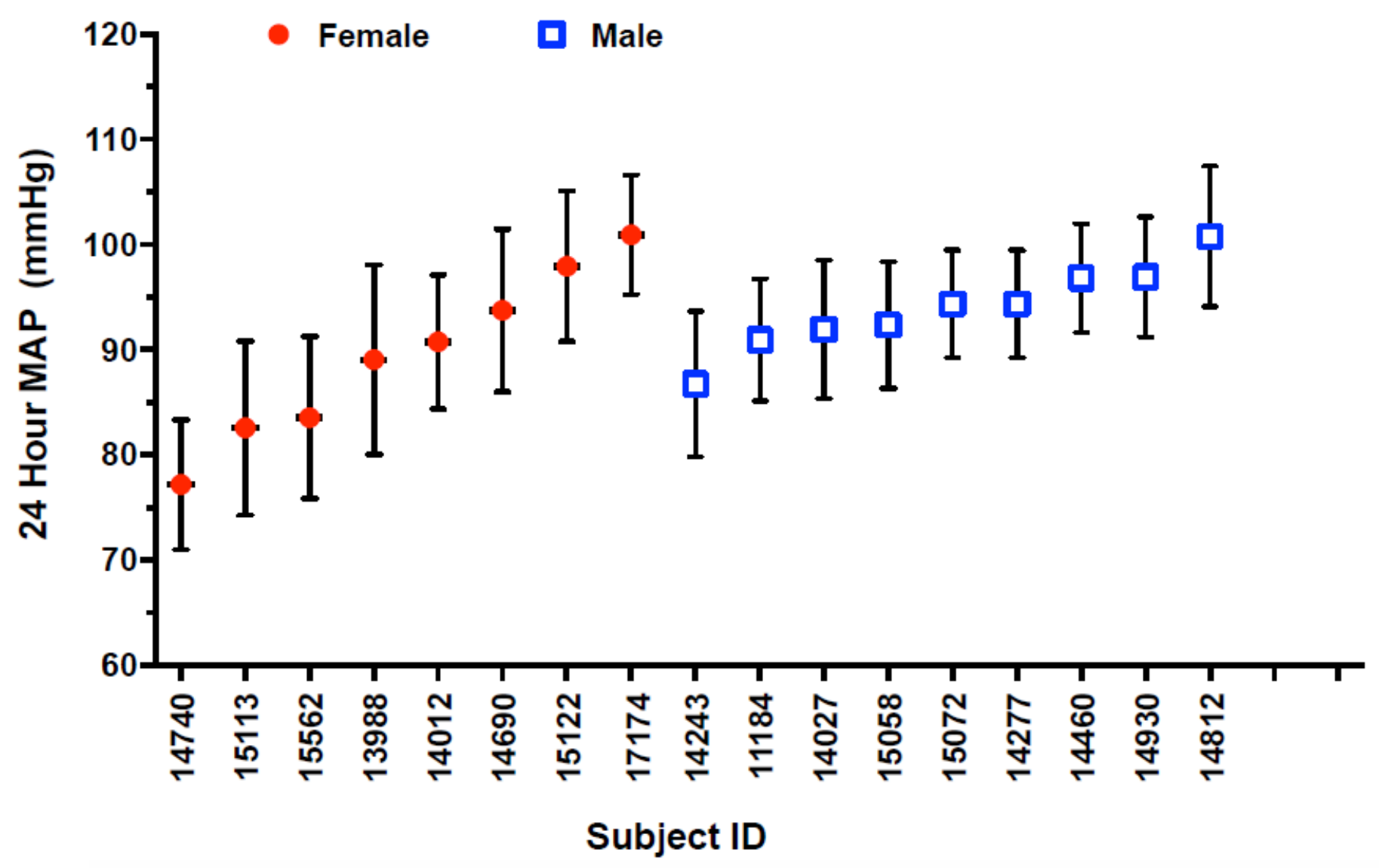

Figure 1

Mean arterial pressure (MAP) over 24-hours in female and male baboons. Animal ID is represented for each animal along the $x$-axis, and 24-hour MAP $(\mathrm{mmHg})$ is shown along the $y$-axis. Mean values for each animal are represented as columns, and bars represent standard deviation. 

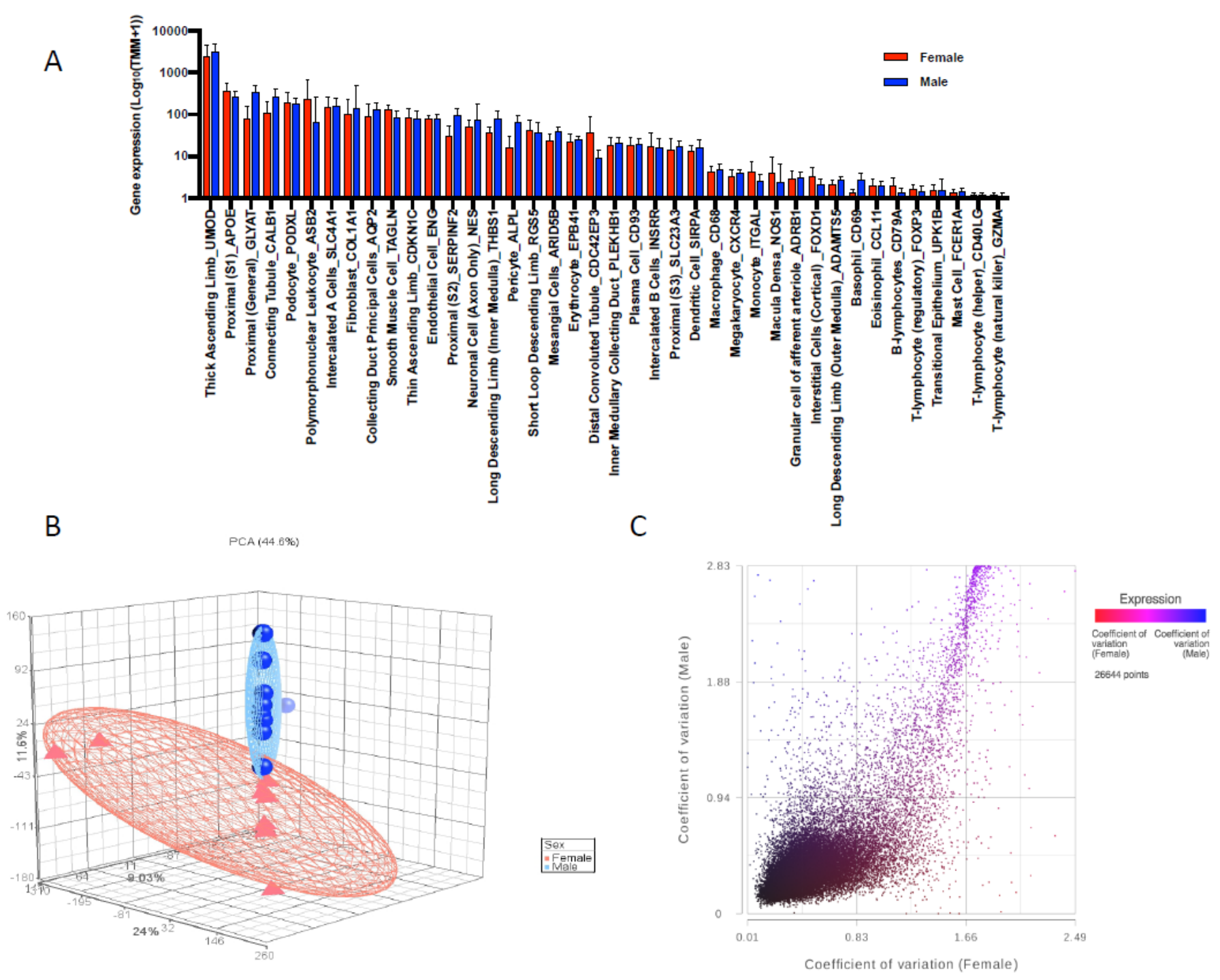

Figure 2

Variation in gene expression of female $(n=8)$ and male $(n=9)$ kidney cortex biopsies. A. Cell type distribution by gene expression in female and male $(n=9)$ kidney cortex biopsies. Mean expression values reported for each gene as the $\log (\mathrm{TMM}+1)$ are represented as columns, and bars represent standard deviation. The $x$-axis is labeled according to cell type and corresponding gene name. B. Principal components analysis of female and male kidney cortex transcriptomes. Top principal components total $44.6 \%$ represented with each axis as follows: $1=24 \%, 2=11.6 \%, 3=9.03 \%$. Each female transcriptome is represented as a red triangle and each male transcriptome as a blue sphere. Ellipsoids denote 2 standard deviations from the mean for each group. C. Coefficient of variation in 26,644 female and male kidney cortex biopsy transcripts. Each point demonstrates a single transcript with a particular coefficient of variation value in females on the $x$ axis $(n=8)$ and males $(n=9)$ on the $y$ axis. The color of each point indicates if the transcript expression level is greater in females (red) or males (blue). 


\begin{tabular}{|c|c|c|c|c|}
\hline $\begin{array}{l}-0.41 \\
(0.3)\end{array}$ & $\begin{array}{l}-0.11 \\
(0.8)\end{array}$ & $\begin{array}{l}-0.31 \\
(0.4)\end{array}$ & $\begin{array}{l}-0.11 \\
(0.8)\end{array}$ & $\begin{array}{l}-0.28 \\
(0.5)\end{array}$ \\
\hline $\begin{array}{c}-0.096 \\
(0.8)\end{array}$ & $\begin{array}{l}-0.2 \\
(0.6)\end{array}$ & $\begin{array}{l}0.034 \\
(0.9)\end{array}$ & $\begin{array}{l}-0.36 \\
(0.3)\end{array}$ & $\begin{array}{l}-0.14 \\
(0.7)\end{array}$ \\
\hline $\begin{array}{l}0.29 \\
(0.4)\end{array}$ & $\begin{array}{c}-0.078 \\
(0.8)\end{array}$ & $\begin{array}{c}-0.0041 \\
\text { (1) }\end{array}$ & $\begin{array}{l}0.16 \\
(0.7)\end{array}$ & $\begin{array}{l}0.19 \\
(0.6)\end{array}$ \\
\hline $\begin{array}{c}0.75 \\
(0.02)\end{array}$ & $\begin{array}{l}0.28 \\
(0.5)\end{array}$ & $\begin{array}{l}0.47 \\
(0.2)\end{array}$ & $\begin{array}{c}0.66 \\
(0.05)\end{array}$ & $\begin{array}{c}0.79 \\
(0.01)\end{array}$ \\
\hline $\begin{array}{l}0.47 \\
(0.2)\end{array}$ & $\begin{array}{l}-0.18 \\
(0.7)\end{array}$ & $\begin{array}{l}0.045 \\
(0.9)\end{array}$ & $\begin{array}{l}0.54 \\
(0.1)\end{array}$ & $\begin{array}{c}0.7 \\
(0.04)\end{array}$ \\
\hline $\begin{array}{c}0.2 \\
(0.6)\end{array}$ & $\begin{array}{l}0.043 \\
(0.9)\end{array}$ & $\begin{array}{l}0.058 \\
(0.9)\end{array}$ & $\begin{array}{l}0.13 \\
(0.7)\end{array}$ & $\begin{array}{l}0.17 \\
(0.7)\end{array}$ \\
\hline $\begin{array}{l}0.56 \\
(0.1)\end{array}$ & $\begin{array}{l}0.45 \\
(0.2)\end{array}$ & $\begin{array}{l}0.51 \\
(0.2)\end{array}$ & $\begin{array}{l}0.31 \\
(0.4)\end{array}$ & $\begin{array}{l}0.33 \\
(0.4)\end{array}$ \\
\hline $\begin{array}{l}0.28 \\
(0.5)\end{array}$ & $\begin{array}{c}0.5 \\
(0.2)\end{array}$ & $\begin{array}{l}0.51 \\
(0.2)\end{array}$ & $\begin{array}{l}0.063 \\
(0.9)\end{array}$ & $\begin{array}{l}0.091 \\
(0.8)\end{array}$ \\
\hline $\begin{array}{l}0.43 \\
(0.3)\end{array}$ & $\begin{array}{c}0.72 \\
(0.03)\end{array}$ & $\begin{array}{c}0.72 \\
(0.03)\end{array}$ & $\begin{array}{l}0.25 \\
(0.5)\end{array}$ & $\begin{array}{l}0.22 \\
(0.6)\end{array}$ \\
\hline $\begin{array}{l}0.57 \\
(0.1)\end{array}$ & $\begin{array}{l}0.28 \\
(0.5)\end{array}$ & $\begin{array}{l}0.27 \\
(0.5)\end{array}$ & $\begin{array}{l}0.42 \\
(0.3)\end{array}$ & $\begin{array}{c}0.4 \\
(0.3)\end{array}$ \\
\hline 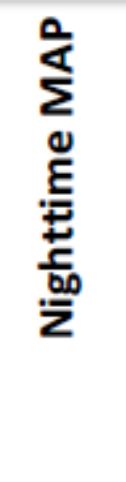 & 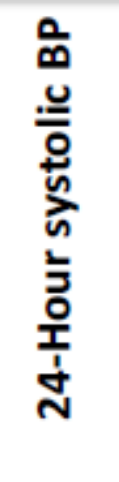 & 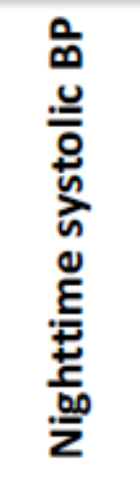 & 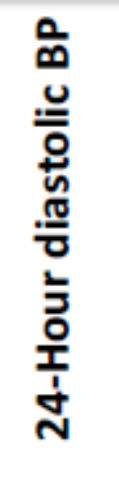 & 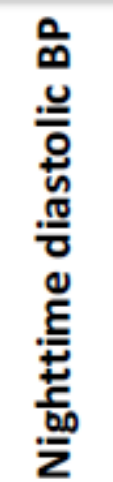 \\
\hline
\end{tabular}

\section{Figure 3}

WGCNA of traits correlated with transcript modules in male baboons on low-sodium chow diet $(n=9)$. Each colored block along the left side represents a module of transcripts correlated with each other. Topvalues in each block represent correlation, bottom values in each block represent $p$-values for each transcript module and trait. Color scale on the right side of the heatmap corresponds to correlation $r$ values of each square. Abbreviated measures along the $x$-axis represent the following measures: nighttime MAP (mmHg), 24-hour systolic BP $(\mathrm{mmHg})$, nighttime systolic BP $(\mathrm{mmHg})$, 24-hour diastolic BP $(\mathrm{mmHg})$. 


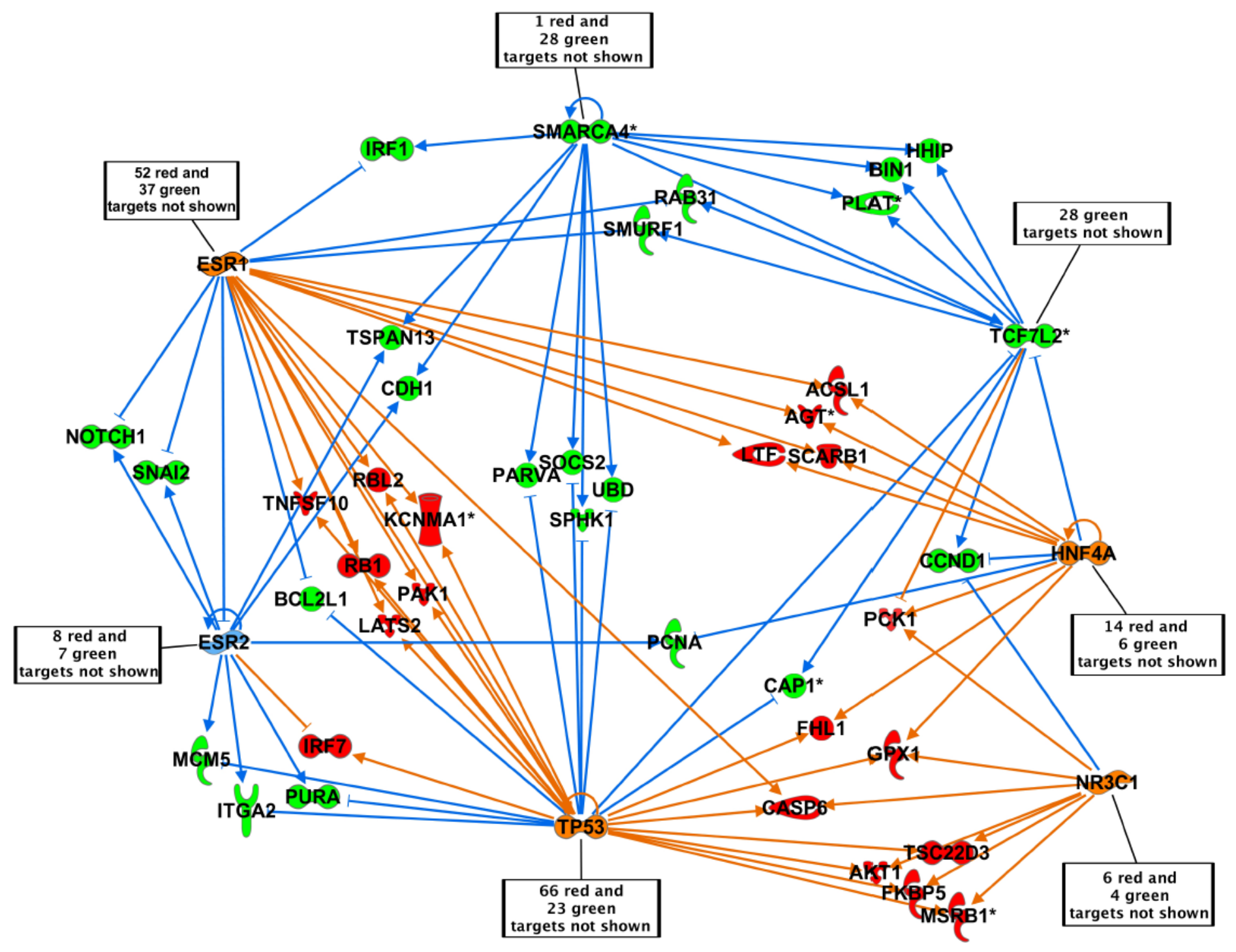

Figure 4

Network analysis of WGCNA transcripts correlated with BP in males. Upstream regulators of transcripts and targets are shown; upstream regulators are identified as having a box indicating "targets not shown" branching off. Molecules in orange are genes predicted as activators, and genes in red are positively correlated with BP in the dataset. Molecules in blue are genes predicted as inhibitors, and genes in green are negatively correlated with BP in the dataset. Arrows indicate direction of activation of downstream gene, and $T$ lines represent inhibition of downstream gene. Orange lines indicate target activation supported by the literature, blue lines indicate target inhibition supported by the literature.

\section{Supplementary Files}

This is a list of supplementary files associated with this preprint. Click to download.

- AdditionalFile1.xlsx

- AdditionalFile2.pdf 